\title{
Urban Iron and Steel Waste Landscape
}

\author{
Yijie Liu ${ }^{1}$ and Yunshi Zhou ${ }^{2}$ \\ ${ }^{1}$ College of Art and Design of Wuhan University of Science and Technology, Art and Design \\ Department, Hubei Province, Wuhan City 430081; \\ ${ }^{2}$ Wuhan University of Science and Technology, Hubei Province, Wuhan City 430081
}

\begin{abstract}
Creating a good urban environment is an important mark of urban modernization during a new century: comfortable Eco-environmental system, cultural-advanced spirits, ypically wonderful city landscape. However, in our current era with rapid development, urbanization is also bound to bring about environmental pollution. So is Wuhan as a central area in China. WISCO, as the leading enterprise in Wuhan, has become one of the world-top 500 super joint steel companies whose yearly waste emission isn't also ignored. Tremendous solid waste is produced in the process of steel production in the factory including Tailings, sludge, slag, fly ash and industrial waste etc. Therefore, it's urgent for Wuhan as the city of Iron and steel to recycle these wastes. Today people have already had new understanding and insight into the beauty of city-coexistence of form and color, shared development of culture and environment. If these steel wastes are collected intensively and redesign to embellish our city, it not only solves the low efficiency of steel wastes recycling, but beautify urban environment and upgrade urban quality.
\end{abstract}

Keywords: Scraped steel; Recycle; Steel experience area; Civic landscape; Sustainable development

\section{城市化钢铁废弃物景观}

$$
\text { 刘艺洁 } 1^{1}, \text { 周韵诗 } 2^{2}
$$

(1. 武汉科技大学艺术与设计学院、艺术设计系, 湖北省武汉市 430081 ;

2. 武汉科技大学, 湖北省武汉市 430081)

摘要: 迈向新世纪城市现代化的重要标志是营造一个良好的城市环境: 舒适宜人的生态体系, 文明高效的精神风貌, 富 有特色的优美城市景观。但是在现在这个飞速发展的年代, 城市建设同时往往也带来了环境的污染。作为华中地区的武汉同 样是如此，作为武汉龙头企业的武钢，全世界前 500 强的超级联合制钢企业，每年排放的废弃物也是不容小视的。钢铁厂在 炼钢的过程中, 要产生大量的固体废弃物, 其中这些废弃物分别指的是尾矿、尘泥、冶炼渣、炉渣、粉煤灰以及工业垃圾等。 这些钢铁的废弃物的回收再利用也正是对于武汉这个 “钢铁之城” 首要要解决的问题。在今天人们对城市的美的领悟又有了 新的理解和认识, 形式与色彩并存, 文化与环境同发展。如果能将这些钢铁废弃物集中回收起来, 加之以设计, 然后运用到 我们的城市景观之中, 那么不仅仅的解决了钢铁废弃物回收后利用率低的问题, 同时也美化了城市的环境, 提高了了城市 品位。

关键词: 废弃钢铁; 回收利用; 钢铁体验区; 城市景观; 可持续发展

引言

时代的变更要求城市同步发展，改造城市面貌、提升城市功能、提高城市品位成了城市发展的首要之 务。武汉是华中地区最大的工业城市和商业城市, 他是国家重点建设的工业城市, 拥有钢铁冶炼、汽车制 造、光电子产品、化工产品、治金、纺织、造船、加工制造、医药等完整的工业体系。清末及民国时期，武 汉经济位居亚洲前列。新中国成立后, 武钢、武重、武锅、武船、肉联等一大批企业陆续建成, 极大地提 升了武汉的经济地位和城市实力。作为武汉龙头企业的武钢, 全世界前 500 强的超级联合制钢企业, 每年 
排放的废弃物也是不容小视的。钢铁厂在炼钢的过程中，要产生大量的固体废弃物，其中这些废弃物分别 指的是尾矿、尘泥、治炼渣、炉渣、粉煤灰以及工业垃圾等。这些钢铁的废弃物的回收再利用也正是对于 武汉这个 “钢铁之城” 首要要解决的问题。在今天人们对城市的美的领悟又有了新的理解和认识, 形式与 色彩并存，文化与环境同发展。如果能将这些钢铁废弃物集中回收起来，加之以设计，然后运用到我们的 城市景观之中，那么不仅仅的解决了钢铁废弃物回收后利用率低的问题，同时也美化了城市的环境，提 高了了城市品位。

所以此次设计以钢铁废弃物的回收再利用为主题，将废弃钢铁变废为宝，运用到我们的城市景观中 去。因地制宜，将青山区沿港路段打造成一个钢铁体验区，在本次设计之中大家可以看到废弃钢铁是怎么 运用到我们的城市景观之中，废弃的钢铁通过简单的加工，变成了树池、花坛、景观构筑物、景观雕塑、 公交车站、人行天桥等我们日常生活中经常看到的城市景观，把沿港路段打造成了一个富有主题特色的钢 铁体验区，让大家不仅仅看到了后工业时代的产物钢铁是怎么回收利用，同时也看到了这些钢铁废弃物 是怎么来包装我们的城市，怎么样来美化我们的城市。

\section{1 设计的出发点}

时代的进步，社会的飞速发展，人类居住环境的质量也日益收到了关注, 但是在当代这个进步大的背 景之下，整个人类却无可置疑的存在着 “生存的危机” ，后工业时代城市的飞速发展带来了环境的恶化， 随意摆放的固体废弃物与生活垃圾在城市中处处可见。许许多多因为建设所造成的破坏，发展性的危机， 时时刻刻在地球的每一个角落发生, 因此可持续发展与现代建设和自然环境相融合是本次设计的理念动 机来源之一。

大规模、大批量求 “速度” 的建设使得城市中千篇一律的建筑形式与城市景观使现在的城市失去了主 题与特点, 城市景观不单单的只是一种设计现象, 它更是一种文化的体现, 同时也是现代人对于精神需 求的一种映射, 这也就是本次设计的理念动机来源之二。

此次设计的基地选址为武汉青山区沿港路段与青山港之间的那块区域，占地面积为，因为武汉整个 青山区的经济百分之八十都是当地的龙头产业武汉钢铁厂带动着，因此借机希望通过武汉钢铁厂排放的 钢铁废弃物为当地来营造一种新的带有明显地域特色的城市景观体验区，既解决武汉钢铁厂钢铁废弃物 的排放问题，美化了城市环境，又刺激了当地的旅游消费，增加了就业率。这为本设计的选址动机来源。

\section{2 设计的目的及意义}

可持续发展在这个名词在当今的社会随处都可以看到它的踪影，正是因为这个名词的存在，所以我 们当今生存的环境才慢慢的被得以重视，如果将这个名词运用到我们的城市建设当中，何乐而不为呢？ 既保护了环境，又美化了我们的城市，提高了了人们的生活品质。

1）通过武汉钢铁厂废弃钢铁的回收在次利用，做到可持续发展，减少废弃资源的浪费，通过设计运用到 沿港路段的城市景观之中，以此给人类展示后工业时代人们的工业建设与大自然是怎么完美结合的，给 人以启迪，呼吁全人类重视对人们赖以生存的地球给给以保护。

2）经过设计从新改造沿港路段，使之成为 “钢铁体验区”，不仅仅为当地发展了旅游经济，刺激了当地 的消费，同时也增加了当地周围的就业率，缓解了失业的情况。

经过设计从新改造现场，使之在一些死角的地方不会像以前那样随意摆放垃圾废品，从而做到了改 
善当地环境的目的。

就地取材, 利用武汉钢铁厂的工业废钢, 将当地打造成为一个主题鲜明带有当地特点的城市文化景 观，不仅仅的是废物再次利用，从而也贯穿了整个青山区以武钢为核心的总体思想，把青山区打造成为 了与其他几个区不相同，钢铁主题鲜明的区域，刺激了整个武汉的文化旅游业。

\section{3 设计研究对象}

\section{1 研究对象及内容}

以武汉市沿港路段城市景观体验区的设计，使对武汉钢铁厂所排放的废弃钢铁，然后以艺术的手法 加工和设计将其运用到当代的城市景观之上，美化环境的同时将武汉沿港路原有过时没有城市特征的城 市景观替换掉，使交通流线不是很通畅的当地变得顺畅，武汉市沿港路段钢铁体验区设计除了阐述后工 业时代的废弃钢铁怎么去加之以利用之外, 通过各个节点的设计将整个体验区完美融合到了一体。通过分 析了当地的现状、交通流线、天际线, 再使当地环境得到改善的同时, 也将当地建设成为了一个大型娱乐 休闲的体验场所，让人感受青山区的钢铁文化的延续。

\section{2 可持续发展与题材分析}

废弃资源的回收再次利用运用到当代的城市景观之中, 这是当今可持续发展研究课题的重中之重, 废弃资源回收后从新组合，再次利用意味着将大大减少人们对于废弃资源的的抛弃以至于对环境的破坏。 炼钢过程中产生废弃钢铁的再次利用已作为钢厂怎么使资源最大化利用的头等战略目标，本次设计的题 材是将武汉钢铁厂炼钢之后所产生的废弃钢铁固体物通过简简单单的加工，甚至直接搬运的方式，通过 后期的再次组合来美化沿港路段, 使之成为钢铁体验区。整个体验区给前来参观、体验的人群阐述着整个 炼钢的过程以及钢铁的历史和钢铁在人类 2) 生活中的重要性, 同时也告诉人类，并且启迪保护环境做到 可持续发展是人们在这个大的背景下的重中之重。

\section{4 设计理念}

\section{1 概念构思}

在设计之中希望达到自然景观、城市、情感、想象力相结合的方式，来阐述后工业时代人类的飞速建 设与自然环境怎么去相协调, 怎么做到可持续发展。希望将大自然的绿色与和谐和钢筋混凝土的现代城市 相结合, 抹去无情的 “味道”, 并且加以想象力, 融合当地富有特征的元素钢铁将沿港路段钢铁体验区 打造成一个富有明显主题色彩的城市风景线。使当地文化与建筑景观相融合, 给忙碌的人们创造一块可以 休憩、娱乐的区域。

\section{2 功能分析}

凌乱的废弃钢丝加上钳子八字形与当地完美结合的流线造型使我有了很好的设计灵感，从而使整个 区域采用合、分、合、分、合的交接模式，使得参观的人群在其中游玩体验的时候有着高低起伏的抖动，顿 时激动，顿时平静。整个体验区分为了 “铁城堡” (合) + “穿越时空” (分) + “钢林” 大道（合）+ “钢 铁音乐盒”（分）+ “大脚掌极限运动场”（合）=六大节点（完美的结合）。

\section{3 铁城堡区域}

“铁城堡”———铁城堡” 是老化遗弃的锅炉改造而成, 里面改造成大型娱乐场所, 其中有 “梦幻 冰工厂” 大型滑冰场, “黑玫瑰” 大型主题酒吧, “梦幻天神” 大型主题餐厅、旅馆。每年在此还会举办 
许多园区内的节日，以此来丰富体验区内部的活动，使体验区一年十二个月十二种景色，内部活动项目 一直保持新鲜感, 独特创新, 以此来增加前来旅游体验的人群。

“铁之记忆” 广场——此广场是利用钢厂废弃老化的零部件随意组合, 打造成为许多有创意的雕塑 景观，广场中间还有长达十米的 “记忆” 铁板，阐述着钢铁的历史以及当今对于炼钢过程中钢铁废弃物 的处理方式, 以及通过设计现在的体验区的处理方式。

“苏醒”台一一此区域是利用废弃钢渣用艺术的手法变废为宝, 加以机理效果, 向大家展示后工业 时代的的艺术。一个个不同 “苏醒” 台的让人们了解钢铁再次利用的方法以及过程。讲述着废弃钢铁的 “复生”。

\section{5 植物配置分析}

整个钢铁体验区以废弃钢铁为元素进行搭建, 从而避免不了因为钢铁的原有属性的存在, 钢铁坚硬 分明的轮廓与灰冷色调的属性会与整个环境显得不协调, 但是在本次设计之中运用植物的配置来模糊化 了这一系列的问题。

乔木: 以落叶的法国梧桐作为行道树, 加之以常绿的法国为冬青的点缀, 使之在落叶的季节幻想翩 翩。其余地方多用香樟、广玉兰、乐昌含笑、桂花、石楠、雪松等常绿乔木作为背景树, 其中穿插银杏、 合欢、白玉兰、紫荆、红枫、樱花、红叶李、结香等落叶乔木, 前方用棕榈和苏铁加以点缀, 使得整个体 验区一年四季有着不同的颜色, 别有一番风味。

灌木: 路边的常绿灌木以金边黄杨为主, 穿插着杜鹃为点缀, 使之更好的匹配整个场地的流线型造型 设计。落叶灌木选用丁香、红叶李、腊梅、木槿、红叶小檗、迎春、木芙蓉。

草本花卉: 本体验区采用美人蕉、百合、金边龙舌兰、小苍兰、一叶兰、大丽花、彩叶草三色堇、芳 药、太阳花、向日葵、牵牛花为整个体验区增加亮度。

藤本植物：体验区内部大量运用木香、葡萄、常春藤、紫藤、藤本月季等藤本植物对景观构筑物作为 垂直绿化, 使之来柔化钢铁的本质属性, 提高整个园区的和谐程度。

\section{6 结论}

社会在进步, 时代在发展, 工业的蓬勃发展是整个社会前进的动力, 但是在社会前进的道路上并非 一帆风顺, 因为人类在改造自然建设的过程中造成了大量的废弃物的排放, 建设的同时也在毁灭人类自 己，因此废弃资源的再次利用是为了减少人类过度的开采新资源的新措施，做到可持续发展，为人们生 活和的环境打造一个舒适的城市和氛围。

本次设计以武汉钢铁厂废弃钢铁回收再利用改造为城市景观为主题, 通过这次设计, 以武汉市沿港 路段为设计基地, 向人们展示了武汉钢铁厂在冶炼过程中废弃固体物通过回收设计后在城市景观中的运 用，以及呼吁大家重视对环境的保护，做到可持续发展。同时在保护环境的同时，用废弃钢铁来装点我们 的城市，使之符合青山区 “十里钢城” 的称号, 让当地具有浓厚的钢铁主题气息。希望通过本次设计能够 阐述我对当代城市景观的发展的想法, 做到又环保、又有特色的主题城市景观, 使整个城市富有特色, 富 有生机，与众不同，延续当地的民生民俗。 


\section{7 致谢}

此论文由教育厅人文社科课题，工业固体废弃物在园林景观中的应用 $16 Y 020$ 支持

\section{参考文献:}

[1] 王克勤, 赵瑗, 等. 园林生态城市一城市可持续发展的理想模式 [J]. 浙江林学院学报, 2002 (1)

[2] 严玲璋. 略论 21 世纪上海城市绿化的可持续发展 [J]. 中国园林, 1998

[3] 吴伟，等. 城市特色研究与城市风貌规划 [M]. 同济大学出版社, 2007

[4] 庄伟强. 固体废物处理与利用 [M]. 北京: 化学工业出版社, 2001

[5] 杨吉林. 钢铁工业固体废物治理仁 [M]. 北京: 中国环境科学出版社, 2002

[6] 刘滨谊. 现代景观规划设计 [M]. 南京: 东南大学出版社, 1999

[7] 刘蔓. 景观艺术设计 [M]. 重庆: 西南师范大学出版社, 2000

[8] 于艳春. 王新宇. 天津临港工业区景观河公园景观营造的可持续思考 [J]. 天津园林, 2009

[9] 高慧敏. 论现代钢铁工业建筑的景观与环境设计 [J]. 工业建筑, 2008, 38 (9)

\section{References:}

[1] Wang Keqin, Zhao Yuan, etc. Landscape Ecological City-Ideal Model of Sustainable Urban Development [J].Journal of Zhejiang Forestry College,2002(1)

[2] Yan Lingzhang. Brief Discuss Sustainable Development of 21 Century Urban Greening in Shanghai [J].Chinese Landscape Architecture, 1998

[3] Wu Wei,etc. Urban Characteristic Research and City Planning [M].Tongii University Press, 007

[4] Zhuang Weiqiang. Solid Waste Disposal and Utilization [M].Beijing: Chemical Industry Press, 2001

[5] Yang Jilin. Steel Industry Solid Waste Management [M].Beijing: China Environmental Science Press, 2002

[6] Liu Binyi. Modern Landscape Planning and Design [M].Nanjing: Southeast University Press, 1999

[7] Liu Man. Landscape Design [M].Chongqing: Southwest China Normal University Press,2000

[8] Yu Yanchun, Wang Xinyu. Sustainable Thinking on Park Landscape of Landscape River in Tianjin Lingang Industrial Area [J].Journal of Tianjin

[9] Landscape Architecture, 2009 Gao Huimin. On Landscape and Environmental Design of Modern Iron and Steel Industrial Building [J].Industrial Construction Magazine Agency, 2008,38(9) 